\title{
Research in brief: Inpatient hip fractures and nomenclature of delirium and acute encephalopathy
}

\author{
Authors: Tessa M Cacciottolo ${ }^{A}$ and Laura Ferrigan ${ }^{B}$
}

DOI: $10.7861 /$ clinmed.rib.20.3

\section{Inpatient hip fractures: understanding and} addressing the risk of this common injury

Elderly patients represent an increasing proportion of the general medical take and of the inpatient population in our hospitals. ${ }^{1}$ Older patients are at increased risk of falls while in hospital. Most falls are multifactorial in nature. Delirium in the context of acute illness and unfamiliar surroundings, compound pre-existing frailty, comorbidities and polypharmacy. ${ }^{2}$ Hip fractures are the most common serious injury in older people and are associated with long-term disability and loss of independent living. ${ }^{3}$

Recent work by Singh et al examines the circumstances leading to inpatient hip fractures and subsequent outcomes. ${ }^{4}$ Through retrospective review of all inpatient falls resulting in hip fractures within the Aneurin Bevan University Health Board in Wales between January 2016 and December 2017, they establish a mean falls rate of $8.7 / 1,000$ occupied bed days, with an inpatient hip fracture rate of 0.12/1,000 occupied bed days $(n=118)$. Forty-five per cent of all fractures happened after the first inpatient fall. As seen in previous studies, most falls were multifactorial - on average, more than four factors contributed to each fall. ${ }^{2,3}$ The top risk factors included a history of falls in the past 12 months, a history of dementia or cognitive impairment, walking with mobility aids, polypharmacy and immobility due to weakness or pain. While $28 \%$ of patients had a history of fragility fractures, only $39 \%$ of these were treated for osteoporosis. In keeping with findings from the National Hip Fracture Database, most falls seemed to coincide with evening staff changeover times. ${ }^{3}$ Finally, inpatient hip fractures have a strikingly poor prognosis; $95 \%$ of patients were admitted from their own home, but only $43 \%$ were discharged back there. The inpatient mortality was $30 \%$ - more than double that for community hip fractures.

Authors: ${ }^{A}$ National Institute for Health Research clinical lecturer in gastroenterology, Addenbrooke's Hospital, Cambridge, UK; ${ }^{B}$ consultant geriatrician, Surrey and Sussex Healthcare NHS Trust, Redhill, UK
The findings in this study highlight the importance of undertaking a comprehensive assessment of modifiable falls risk factors for all acute admissions above the age of 65 years, with particular attention paid to the management of osteoporosis where appropriate. ${ }^{5,6}$

\section{References}

1 NHS Digital. Hospital admitted patient care and adult critical care activity: 2018-19. NHS, 2019. https://files.digital.nhs.uk/F2/ E70669/hosp-epis-stat-admi-summ-rep-2018-19-rep.pdf

2 Hopewell S, Copsey B, Nicolson P et al. Multifactorial interventions for preventing falls in older people living in the community: a systematic review and meta-analysis of 41 trials and almost 20000 participants. Br ] Sports Med 2019 [Epub ahead of print].

3 Royal College of Physicians. National hip fracture database: annual report 2017. London: RCP, 2017. www.nhfd.co.uk/ files/2017ReportFiles/NHFD-AnnualReport2017.pdf

4 Singh I, Hooton K, Edwards C et al. Inpatient hip fractures: understanding and addressing the risk of this common injury. Age Ageing 2020;49:481-6.

5 National Institute for Health and Care Excellence. Falls in older people: assessing risk and prevention: Clinical guideline [CG161]. NICE, 2013. www.nice.org.uk/guidance/cg161

6 National Institute for Health and Care Excellence. Osteoporosis: assessing the risk of fragility fracture: Clinical guideline [CG146]. NICE, 2017. www.nice.org.uk/guidance/cg146

\section{Updated nomenclature of delirium and acute encephalopathy: statement of 10 societies}

Patients with acute illness can commonly acquire an acute, global disturbance in cognition - affecting one-third of patients over the age of 70 years who are admitted to hospital. ${ }^{1,2}$ It is associated with increased long-term morbidity. ${ }^{3}$ A better understanding of predisposing factors, prevention and management, represents an area of unmet clinical need.

A recent article in Intensive Care Medicine tackles the variable terminology used to describe acute cognitive dysfunction (delirium, encephalopathy, acute confusional state, acute brain failure and altered mental status). ${ }^{4}$ Through an extensive literature review, the authors demonstrate that use of the terms 'encephalopathy' and 'delirium' are favoured separately by investigators from different disciplines; neurology, neurosciences, general/internal medicine journals published more articles with 
Table 1. Standardised nomenclature associated with acquired acute cognitive dysfunction

$\begin{array}{llll}\text { Name } & \begin{array}{l}\text { Definition } \\ \text { Acute encephalopathy } \\ \text { Change from baseline cognitive } \\ \text { Status. }\end{array} & \begin{array}{l}\text { Time course } \\ \text { Rapidly developing } \\ (<4 \text { hours }) .\end{array} & \begin{array}{l}\text { Cause } \\ \text { Pathobiological process in the } \\ \text { brain. }\end{array} \\ & \begin{array}{l}\text { Disturbance in attention, cognition } \\ \text { and awareness, not explained by } \\ \text { another neurocognitive disorder or } \\ \text { reduced level of arousal. }\end{array} & \begin{array}{l}\text { Hours to few days. Tends to } \\ \text { fluctuate. }\end{array} & \begin{array}{l}\text { Direct physiologic consequence } \\ \text { of another medical condition, } \\ \text { intoxication, withdrawal, toxin } \\ \text { exposure or multiple aetiologies. }\end{array} \\ & \begin{array}{l}\text { Severely depressed responsiveness. } \\ \text { Coma }\end{array} & \text { Variable. } & \begin{array}{l}\text { May follow acute encephalopathy } \\ \text { or delirium. }\end{array}\end{array}$

'encephalopathy' in the title, whereas geriatrics, psychiatry and intensive care / anaesthetics journals published more articles with 'delirium' in the title. This segregation in the literature leads to confusion and poses a barrier to research in the field more broadly. 4,5

The aim of this consensus statement is to standardise the nomenclature associated with acquired acute cognitive dysfunction. Definitions were created, refined and voted on using the modified Delphi method by an international panel of experts from a range of disciplines (Table 1).

The panel recommends that these terms should not be used: 'acute confusional state' (use delirium or acute encephalopathy instead); acute brain dysfunction; brain failure; and altered mental status. -

\section{References}

1 Marcantonio ER. In the clinic: Delirium. Ann Intern Med 2011;154:ITC6-1-16.

2 Marcantonio ER. Delirium in hospitalized older adults. N Engl ] Med 2017;377:1456-66.

3 Witlox J, Eurelings LSM, de Jonghe JFM et al. Delirium in elderly patients and the risk of post-discharge mortality, institutionalization and dementia: a review. JAMA 2010;304:443-51.

4 Slooter AJC, Otte WM, Devlin JW et al. Updated nomenclature of delirium and acute encephalopathy: statement of ten societies. Intensive Care Med 2020 [Epub ahead of print].

5 Morandi A, Pandharipande P, Trabucchi M et al. Understanding international differences in terminology for delirium and other types of acute brain dysfunction in critically ill patients. Intensive Care Med 2008:34:1907-15.

\section{Introducing the RCP's new podcast series: the ClinMeditorial}

Listen to ClinMeditorial, a new series of podcasts featuring editor-in-chief Anton Emmanuel's ClinMeditations on the content of Clinical Medicine journal.

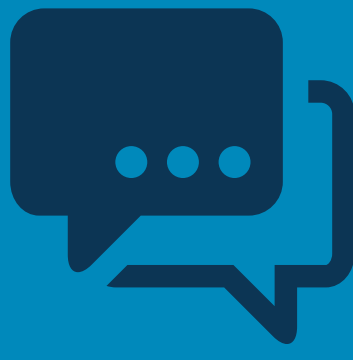

